\title{
SHORT-TERM PLANNING OF HYBRID POWER SYSTEM
}

\author{
Goran Knežević — Zoran Baus — Srete Nikolovski *
}

\begin{abstract}
In this paper short-term planning algorithm for hybrid power system consist of different types of cascade hydropower plants (run-of-the river, pumped storage, conventional), thermal power plants (coal-fired power plants, combined cycle gasfired power plants) and wind farms is presented. The optimization process provides a joint bid of the hybrid system, and thus making the operation schedule of hydro and thermal power plants, the operation condition of pumped-storage hydropower plants with the aim of maximizing profits on day ahead market, according to expected hourly electricity prices, the expected local water inflow in certain hydropower plants, and the expected production of electrical energy from the wind farm, taking into account previously contracted bilateral agreement for electricity generation. Optimization process is formulated as hourly-discretized mixed integer linear optimization problem. Optimization model is applied on the case study in order to show general features of the developed model.
\end{abstract}

K e y w ord s: wind farm, hydropower plant, thermal power plant, market bid, short-term planning

\section{Nomenclature}

$P_{\mathrm{r}}$

$v_{\mathrm{ci}}$

$V_{\mathrm{r}}$

$v_{\mathrm{co}}$

$\xi_{w}$

$n_{w, T}$

$V T P_{w, t}^{n}$

$W P s_{w, t}$ the expected output power of the wind farm $w$ during hour $t$

$Q_{i, t} \quad$ total discharge of hydropower plant $i$ during hour $t$

$Q_{\text {min }, i, g}$ minimum discharge corresponding to technical minimum of power output production unit $g$ in hydropower plant $i$

$Q_{i, g, j, t} \quad$ discharge of segment $j$, unit $g$ of hydropower plant $i$ during hour $t$

$N g_{i} \quad$ number of production units in hydropower plant $i$

$B_{0, i, g, t} \quad$ binominal variable of production unit $g$ in hydropower plant $i$ in hour $t$

$n j_{i, g} \quad$ number of discharge segments of production unit $g$ in hydropower plant $i$

$H_{i, t} \quad$ electricity produced in hydropower plant $i$ in

$H_{\text {min }, i, g} \quad \begin{aligned} & \text { hour } t \\ & \text { electricity produced by the production unit } g\end{aligned}$ of hydropower plant $i$ in hour $t$ during output power that equals the technical minimum of production unit $g$

$\mu_{i, g, j} \quad$ differential production equivalent of segment $j$ of production unit $g$ in hydropower plant $i$

$P_{r, p, t} \quad$ electricity consumed by the pump $p$ in power station $r$ during hour $t$
$P_{\min , r, p} \quad$ electricity consumed by the pump $p$ in power station $r$ in hour $t$ during power that equals the technical minimum of pump unit $p$

$P_{r, p, j, t} \quad$ electricity consumed in segment $j$ of the pump $p$ in power station $r$ in hour $t$

$n p_{r} \quad$ number of pump units in pump station $r$

$b p_{r, p, t} \quad$ binominal variable of pump unit $p$ in pump station $r$ in hour $t$

$n j_{r, p} \quad$ number of segments of pump unit $p$ in pump station $r$

$Q p_{r, t} \quad$ amount of pumped water in pump station $r$ during hour $t$

$\delta_{r, p, 1} \quad$ differential pumping equivalent of the first segment of pump unit $p$ in pumping station $r$

$\delta_{r, p, j} \quad$ differential pumping equivalent of the segment $j$ of pump unit $p$ in pumping station $r$

$M u_{i, t} \quad$ content of upper reservoir in hydropower plant $i$ at the end of hour $t$

$M u_{i, t-1}$ content of upper reservoir in hydropower plant $i$ at the end of hour $t-1$

$S_{i, t} \quad$ spillage from upper reservoir in hydropower plant $i$ during hour $t$

$Q d_{j, t-\tau j, i}$ discharge from lower reservoir in hydropower plant $j$ first upstream of hydropower plant $i$

$S d_{j, t-\tau j, i}$ spillage from lower reservoir in hydropower plant $j$ first upstream of hydropower plant $i$

$V_{i, t} \quad$ local inflow to upper reservoir in hydropower plant $i$ during hour $t$

$\tau_{j, i} \quad$ the delay time for the water flow between hydropower plant $j$ and the closest downstream hydropower plant $i$

$M d_{i, t} \quad$ content of lower reservoir in hydropower plant $i$ at the end of hour $t$

$M d_{i, t-1}$ content of lower reservoir in hydropower plant $i$ at the end of hour $t-1$

$Q d_{i, t} \quad$ discharge from lower reservoir in hydropower plant $i$ during hour $t$

\footnotetext{
* The Faculty of Electrical Engineering, J. J. Strossmayer University of Osijek, Kneza Trpimira 2b, 31000 Osijek, Croatia, goran.knezevic@etfos.hr
} 
$S d_{i, t} \quad$ spillage past from lower reservoir in hydropower plant $i$ during hour $t$

$Q_{i, g, t} \quad$ total discharge of production unit $g$ hydropower plant $i$ during hour $t$

$Q_{\text {maks }, i, g}$ upper limit for discharge for unit $g$ in hydropower plant $i$ during hour $t$

$Q_{\text {maks }, i, g, j}$ upper limit for discharge in segment $j$ for unit $g$ in hydropower plant $i$ during hour $t$

$S_{\text {maks, } i} \quad$ upper limit of spillage of upper reservoir in hydropower plant $i$

$S d_{\text {maks, } i}$ upper limit of spillage of lower reservoir in hydropower plant $i$

$M u_{\mathrm{L}, i} \quad$ lower limit for the content of upper reservoir in hydropower plant $i$

$M u_{\mathrm{U}, i} \quad$ upper limit for the content of upper reservoir in hydropower plant $i$

$M d_{\mathrm{L}, i} \quad$ lower limit for the content of lower reservoir in hydropower plant $i$

$M d_{\mathrm{U}, i} \quad$ upper limit for the content of lower reservoir in hydropower plant $i$

$P_{\text {maks, }, p}$ upper limit of the power used for running pump $p$ in pumping station $r$

$Q d_{\mathrm{L}, i} \quad$ lower limit of the river flow between hydropower plants $i$ and $j$

$Q d_{\mathrm{U}, i} \quad$ upper limit of the river flow between hydropower plants $i$ and $j$

$G_{k, g, t} \quad$ electricity produced in generator $g$ in thermal power plant $k$ in hour $t$

$G_{k, t} \quad$ electricity produced in thermal power plant $k$ in hour $t$

$U_{k, g, t} \quad$ binominal variable of unit commitment of generator $g$ in thermal power plant $k$ in hour $t$ (equals 1 if unit is in operation mode, otherwise equals 0 )

$G_{k, g, \max }$ electricity produced by the generator $g$ of thermal power plant $k$ in hour $t$ during output power that equals the installed capacity of production unit $g$

$G_{k, g, \text { min }}$ electricity produced by the generator $g$ of thermal power plant $k$ in hour $t$ during output power that equals the technical minimum of production unit $g$

$C_{\text {start }}(t)$ start up cost of the production unit $g$ of thermal power plant $k$ after off-line period of $t$ hours

$C_{\text {coldtart }}$ start up cost when the boiler is cooled to room temperature

$\tau \quad$ thermal time constant of the boiler

$C_{\text {fixed }} \quad$ fixed start up cost

$p_{k, g, t}^{n} \quad$ binominal variable of unit commitment of generator $g$ in thermal power plant $k$ in hour $t$ after $n$ hours down time

$C_{k, g}^{n} \quad$ start up cost of the production unit $g$ of thermal power plant $k$ after off-line period of $n$ hours

$S_{t} \quad$ electricity sold on the market in hour $t$

$B_{t} \quad$ electricity bought on the market in hour $t$

$M u_{i, T} \quad$ contents of upper reservoir in power plant $i$ at the end of the planning period

$M d_{i, T} \quad$ contents of lower reservoir in power plant $i$ at the end of the planning period
$\Gamma_{i} \quad$ the set of indices for all power plants downstream of power plant $i$ (including power plant $i$ itself)

$\Gamma_{j} \quad$ the set of indices for all power plants downstream of power plant $i$ (without power plant i) expected future electricity price average production equivalent in power plant $k$ bilateral firm power sales in hour $t$ number of hydropower plants number of thermal power plants number of wind farms number of pump-storage hydropower plants

\section{INTRODUCTION}

The hybrid power system consists of renewable energy and traditional energy sources that are managed together in order to increase efficiency, reduce production costs and increase the total earnings of the observed system [1]. In this paper a hybrid system is assumed, which consists of cascade hydropower plants that can be of different types (run-of-the river, pumped storage, conventional), thermal power plants (coal-fired power plants, combined cycle gas-fired power plants) and wind farms. Increasing the share of electricity produced from renewable energy sources, producers of electric energy from renewable energy sources are capable to make bids on the spot market with a premium on getting the realized market price, resulting in a possible realization of higher earnings compared to participation in the market only in the form of tariff agreements with the fixed price for a fixed period. The optimization process described in this paper provides a joint offer of the hybrid system, and thus the operation schedule of hydro and thermal power plants, the operation condition of pumped-storage hydro plants with the aim of maximizing profits on day-ahead market according to expected hourly electricity prices, the expected local water inflow in certain hydropower plants, and the expected production of electrical energy from the wind farm, taking into account previously contracted bilateral agreements for electricity generation.

The problem of integration of the increasing number of wind power plants in the electric power system is the theme of many papers in the last ten years. In order to solve the problems of non-voluntary dispatching of wind power plants and the evaluation forecast uncertainty of wind blowing, and thus the deviation of actual production of electricity than planned, many of the works propose a joint work of a wind farms and installations which can store electricity. Methods of storing electrical energy in the form of batteries, flywheels, compressed air currently represent a very expensive option of electrical storage. On the other hand, the existing hydropower plants with large reservoirs and pumped-storage hydropower plants are so far the most economical solution to storage of electrical energy, so for that reason in recent years, there has been an increase in the interest of the coordination of the 


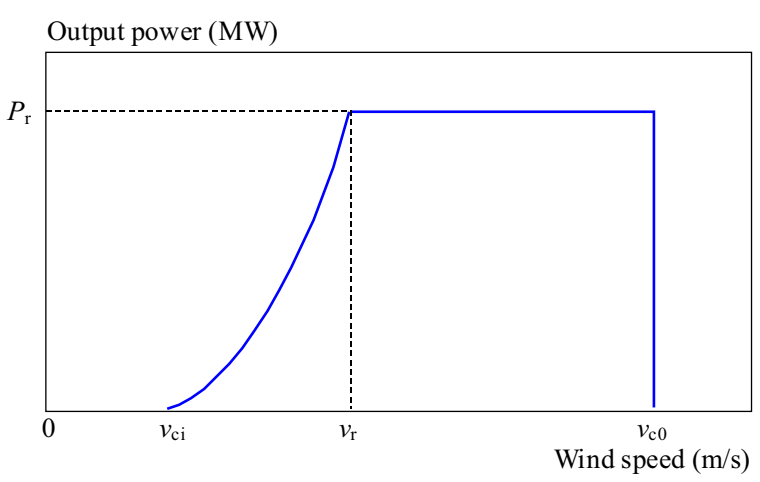

Fig. 1. The proposed input-output characteristic of the wind turbine

hydropower system and wind farms [2]. In [3-6], models of pumped-storage hydropower plant are presented, which will, together with the wind farm meet the demand of electrical energy in insular operation. Optimal coordinated operation of the wind farm and pumped-storage power plant on the islands in the Greek archipelago is considered in [7-10]. In $[11,12]$, the analysis of the combined operation of the wind farm and conventional hydroelectric power plant is shown with the aim of maintaining a constant production of electrical energy in the observed system. In [13-15], the optimization model is formulated, in which, by using mixed integer linear programming, the impact of change in net head of hydropower plants that have low volume of accumulation is taken into account. In [16], the optimization model that determines the optimal hourly dispatch of a pumped-storage hydropower plant is shown, taking into account different tariff prices for electricity. In [17], a comparison of the various strategies of access of wind farms to the electricity market is made. In $[18,19]$ a deterministic linear model for shortterm planning of joint work of the wind farm and hydropower plants in the deregulated market is presented. This model has been improved in [20], where the different scenarios of wind speeds are taken into account by using Monte-Carlo simulation. In [21-24], the influence of the penetration of electricity produced from wind farms on the quantity and price of energy regulation is displayed. These works suggest an increase in requests for the amount of reserves in the system and in the costs of regulation with a rise in installed capacity of wind power plants in the system. In paper [25], a comparison of two scenarios is formed: a separate and joint appearance of wind power plants and hydropower plants on the market. The results show a significant saving in the case of a joint appearance on the market.

\section{OPTIMIZATION TECHNIQUE APPLIED IN THE PROPOSED MODEL}

Mathematical optimization methods allow finding solutions of different problems which demand a minimum or maximum value of the objective function within defined limits. The proposed model for the optimization of the observed production system operation under the conditions of the day-ahead market is presented as an optimization problem of finding the maximum profit that could be solved by mixed-integer linear programming (MILP). MILP allows modeling and solving the problem of linear optimization in which at least some of the variables must be a whole number. The objective function and the default constraints are linear, and the MILP method is used with binary variables, primarily because with integer variables equals 0 and 1 forbidden domains of power plants could be modeled, which can define, for example, the technical minimums of generators and pumps. Models are written in computer code programming language MATLAB, where the MILP problem is solved by the branch and bound algorithm, within which a linear problem is solved by the interior point method.

\section{OPTIMIZATION MODEL OF THE OBSERVED SYSTEM}

\subsection{The model of the wind farm}

Input data for each wind farm are expected wind speeds with an associated discrete probability distribution appearance of a determined wind speed, inputoutput characteristic of the turbines, the number of wind turbines. If the height $z_{r}$, for which the forecasted wind speeds $v$, is different from the height of the wind turbine tower $z$, by using a logarithmic rule [26], the expected wind speeds $v_{e}$ are recalculated to the height that corresponds to the height of the tower

$$
v_{e}(t)=v(t)\left[\ln \left(z / z_{0}\right) / \ln \left(z_{r} / z_{0}\right)\right]
$$

where $z_{0}$ corresponds to a particular parameter according to what is on the surface of the soil in the area of the wind farm (values are defined in [26]).

For the expected electrical energy produced for a given hour, a forecast of the wind speed is used, given in the form of discrete distribution of wind speed with associated probabilities. Discrete distribution of wind speed with $N$ grades in hour $t$ equals

$$
W s_{t}=\left\{v_{e, t}^{1}, v_{e, t}^{2}, \ldots, v_{e, t}^{N_{t}}\right\}
$$

with related probability values

$$
p_{t}=\left\{p_{t}^{1}, p_{t}^{2}, \ldots, p_{t}^{N_{t}}\right\}
$$

Since the production of the wind farm is not being optimized, there is no need for a linear input-output characteristic, but it can be entered for each turbine, according to the actual default data. Also, the input-output characteristic implemented in the algorithm of the proposed model shown in Fig. 1 [27] can be selected. 


\section{Output power (MW)}

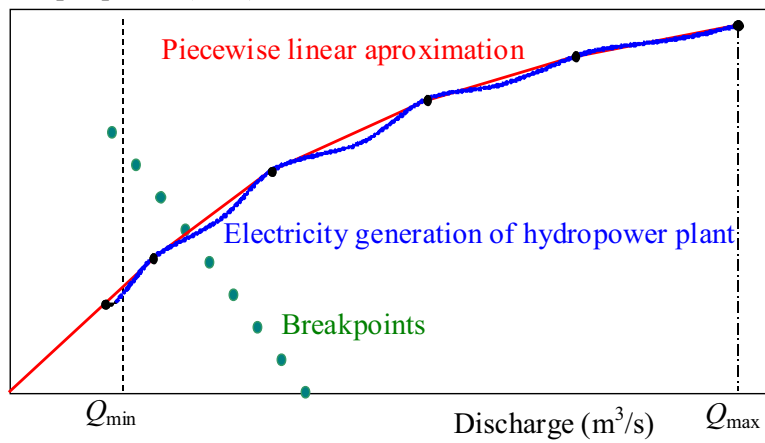

Fig. 2. Linear approximation of the input-output characteristic of the hydroelectric power plant by

The output power of the wind turbine is represented

$$
V T P= \begin{cases}0 & 0 \leq v \leq v_{\mathrm{ci}} \\ \left(A+B v+C v^{2}\right) P_{r} & v_{\mathrm{ci}} \leq v \leq v_{\mathrm{r}} \\ P_{r} & v_{\mathrm{r}} \leq v \leq v_{\mathrm{co}} \\ 0 & v \geqslant v_{\mathrm{co}}\end{cases}
$$

The constants $\mathrm{A}, \mathrm{B}$ and $\mathrm{C}$ are functionally dependent on $v_{\mathrm{ci}}$ and $v_{\mathrm{r}}$, and are calculated using the expression shown in [137].

The assumption is that in the wind farm, all wind turbines (of the same characteristics) have the same output power. However, losses due to the aerodynamic wake losses are taken into account through the wake factor $\xi$. These losses are mainly dependent on the number and spacing of wind turbines, wind turbine characteristics, intensity of turbulences, and so called wind rose [26]. For each discrete distribution value of wind speed (the expression (2)), the corresponding output of a wind farm is calculated:

$$
V P_{w, t}^{n}=\xi_{w} n_{w, T} V T P_{w, t}^{n} .
$$

In this way, a discrete distribution of power output of a wind farm in hour $t$ is obtained by associated probabilities

$$
\begin{aligned}
W P_{w, t} & =\left\{V P_{w, t}^{1}, V P_{w, t}^{2}, \ldots, V P_{w, t}^{N}\right\} \\
p_{t} & =\left\{p_{t}^{1}, p_{t}^{2}, \ldots, p_{t}^{N}\right\} .
\end{aligned}
$$

The expected electric energy produced in the wind farm $w$ in hour $t$ is equal to the value of the average output power during the hour $t$ :

$$
W P s_{w, t}=\sum_{n=1}^{n=N_{t}} p_{t}^{n} V P_{w, t}^{n}(\mathrm{MWh}) .
$$

\subsection{The model of the hydropower plant}

In the proposed algorithm, run-of-the river, storage and pumped-storage hydropower plant can be modeled. In the proposed model, discharge, spillage and reservoir volume are measured at hourly equivalents (HE), which correspond to the water flow of $1 \mathrm{~m}^{3} / \mathrm{s}$ during the time of
1 hour. Physical meaning of HE is also the discharge and volume (depending on context). Volume of accumulation expressed in HE is obtained by dividing the values ??expressed in $\mathrm{m}^{3}$ by 3600 . The power by hydropower plants can be determined from the equation [28]

$$
P_{h}=g Q H_{n} \eta_{t} \eta_{g} \rho(\mathrm{W}),
$$

where $Q$ is the flow through the turbine, $H_{n}$ is the net head, $\eta_{\mathrm{t}}$ and $\eta_{\mathrm{g}}$ are the turbine and generator efficiency, $\rho$ is the density of water and $g$ is the acceleration of the gravitational force.

Due to the definition of linear problems, it is necessary to show the power of the hydropower plant as a linear function of discharge. To avoid complex optimization model, in the proposed algorithm the net head dependency on the flow is neglected. The change in the net head of the discharge can be neglected for hydropower plants that have large upper reservoirs because the change of the upper water level is insignificant when observing the production in the short term. For hydro power plants with small reservoirs this assumption is also valid if the difference between the maximum and minimum levels of the upper water is relatively small compared to the total net head of the hydropower plant $[2,28]$. The dependency of efficiency on the discharge can be taken by segmenting the actual input output characteristic of hydropower plant and on each segment the curve is made to be linear. In this way, a linear function of production is obtained, depending on the discharge for each segment of the hydropower plant. Figure 2 shows an example of the input-output characteristic of the hydropower plant and the associated linear approximation (the variation in net head is neglected).

The discharge segments are determined by break points, which correspond to the local maximum points and the points of minimum and maximum discharge (the size of constructing).

In the proposed algorithm, the input-output characteristic is observed at the level of the production unit, or aggregate (generator with associated turbine). It should be noted that the first segment presents the discharge that corresponds to the technical minimum of the aggregate. In the algorithm, the next segment, after the segment of the technical minimum, is marked with the index $j$ equals 1 , and is the first segment after the segment of the technical minimum. The total discharge of the hydropower plant $i$ in the hour $t$ is

$$
Q_{i, t}=\sum_{g=1}^{n g_{i}}\left[Q_{\min , i, g} b_{0, i, g, t}+\sum_{j=1}^{n j_{i, g}} Q_{i, g, j, t}\right](\mathrm{HE}) .
$$

Production equivalent is defined as the ratio of production and discharge. For a given discharge $Q$ and the corresponding production of $H$ measured in the hour $t$ production equivalent is [29]

$$
\gamma(Q)=\frac{H(Q)}{Q}(\mathrm{MWh} / \mathrm{HE})
$$


Electricity production $H(\mathrm{Q})(\mathrm{MWh})$

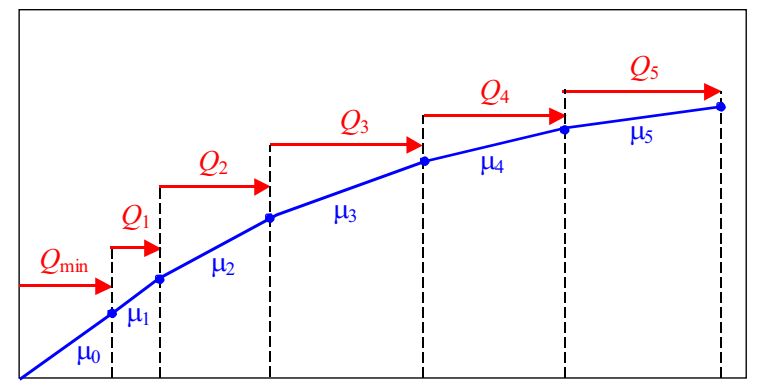

Discharge $Q$ (HE)

Fig. 3. The linear approximation of the input-output characteristic of hydropower plants with the marked segments and corresponding differential production equivalents

Differential production equivalent shows how much production will change with a small change in discharge in one hour [29]:

$$
\mu=\frac{\mathrm{d} H(Q)}{\mathrm{d} Q}(\mathrm{MWh} / \mathrm{HE}) .
$$

Differential production equivalent in the algorithm represents the slope of each segment of the input-output characteristic. Technical minimum of the aggregate can be defined as the minimum discharge or the minimum output power of the aggregate. It is assumed in the model that the differential production equivalent of the technical minimum equal to the differential production equivalent of the first segment after the technical minimum. Electricity produced in hydropower plant $i$ in hour $t$ is

$$
H_{i, t}=\sum_{g=1}^{n g_{i}}\left[H_{\min , i, g} b_{0, i, g, t}+\sum_{j=1}^{n j_{i, g}} \mu_{i, g, j} Q_{i, g, j, t}\right](\mathrm{MWh}) .
$$

Figure 3 shows the linear approximation of the inputoutput characteristic of Fig. 2 with the marked segments and the corresponding differential production equivalent.

Discharge of the segment is equal to 0 if the previous segment is not fully exploited as the segments must be performed in sequence, starting with the segment of technical minimum. To achieve this condition and with it avoid complex optimization model, it was assumed that the differential equivalent of production of each segment is less than in the previous segment, starting from the differential equivalent of production of the first segment after segment of the technical minimum. In this way, segments will be sequentially filled since it is more profitable to use a segment with a greater differential production equivalent [29].

In the algorithm, the user enters the number of aggregates of individual hydropower plant; rated power, technical minimum and rated discharge; number and size of segments for each unit (relative to the nominal flow). The differential production equivalent of the individual segment $j$, of the aggregate $g$, is entered as a percentage value in a relation to the differential production equivalent of the first segment of the aggregate $g$. Input-output characteristic of the pumping operation is linear in a similar manner as the input-output characteristic of the hydropower turbine operation. The total electricity consumed in the operation of the pumping station $r$ during one hour $t$ is

$$
P_{r, t}=\sum_{p=1}^{n p_{r}}\left[P_{\min , r, p} b p_{r, p, t}+\sum_{j=1}^{n j_{r, p}} P_{r, p, j, t}\right](\mathrm{MWh}) .
$$

Differential pumping equivalent shows how the amount of pumped water changes to a slight change of consumed power in the observed hour

$$
\delta=\frac{\mathrm{d} Q(P)}{\mathrm{d} P}(\mathrm{HE} / \mathrm{MWh}) .
$$

The amount of pumped water of the pumping stations $r$ in the hour $t$ is

$$
Q p_{r, t}=\sum_{p=1}^{n p_{r}}\left[P_{\min , r, p} \delta_{r, p, 1} b p_{r, p, t}+\sum_{j=1}^{n j_{r, p}} \delta_{r, p, j} P_{r, p, j, t}\right](\mathrm{HE}) .
$$

The algorithm allows modeling of hydropower plants located on the same river system. In order to facilitate coordination between these hydropower plants, the following condition must be fulfilled in each hour:

new reservoir content $=$ old reservoir content

$$
+ \text { inflow of water - discharging. }
$$

Applying the previous term for the upper reservoir of the hydropower plant $i$, which has a pumping station $r$, we obtain the following condition

$$
\begin{array}{r}
M u_{i, t}=M u_{i, t-1}-Q_{i, t}-S_{i, t}+Q d_{j, t-\tau_{j, i}}+S d_{j, t-\tau_{j, i}} \\
+V_{i, t}+Q p_{r, t}
\end{array}
$$

Applying (16) for the lower reservoir hydropower plant, which has a pumping station $r$ we obtain

$$
M d_{i, t}=M d_{i, t-1}+Q_{i, t}+S_{i, t}-Q d_{i, t}-S d_{i, t}-Q p_{r, t} .
$$

Expressions (17) and (18), also apply to the hydropower plants without pumping station (conventional hydropower plants) with the value of pumped water $Q p_{r, t}$ being 0 for all the time of the simulation.

The assumption is that the time delay of water $\tau_{j, i}$ between the two plants is constant, that is, discharging and spillage of lower reservoir of the upstream hydropower plant will come to the upper reservoir of the first following downstream hydropower plant in a determined number of minutes. The algorithm allows modeling of delays at the level of a minute. If the delay time of water from hydropower plant $j$ to hydropower plant $i$ equals $h_{j}$ hours and $m_{j}$ minutes, the following terms are used for the 
amount of water in the upper reservoir of downstream hydropower plant due to discharge and spillage of the first upstream hydroelectric power plant [29].

$$
\begin{aligned}
Q d_{j, t-\tau_{j, i}} & =\frac{m_{j}}{60} Q d_{j, t-h_{j}-1}+\frac{60-m_{j}}{60} Q d_{j, t-h_{j}}, \\
S d_{j, t-\tau_{j, i}} & =\frac{m_{j}}{60} S d_{j, t-h_{j}-1}+\frac{60-m_{j}}{60} S d_{j, t-h_{j}} .
\end{aligned}
$$

Because of the physical limitations of discharging, the spillage of hydropower plants as well as volumes of reservoirs have upper and lower limits

$$
\begin{gathered}
Q_{\min , i, g} b_{0, i, g, t} \leq Q_{i, g, t} \leq Q_{\text {maks }, i, g} b_{0, i, g, t} \\
0 \leq Q_{i, g, j, t} \leq Q_{\text {maks }, i, g, j} \\
0 \leq S_{i, t} \leq S_{\text {maks }, i} \\
0 \leq S d_{i, t} \leq S d_{\text {maks }, i} \\
M u_{L, i} \leq M u_{i, t} \leq M u_{U, i} \\
M d_{L, i} \leq M d_{i, t} \leq M d_{U, i}
\end{gathered}
$$

Note that in (21), the lower limit represents a product of binomial variable of production unit (equals 0 if production unit is offline, 1 if production unit is online) and discharge that corresponds to the technical minimum of the production unit, while the upper limit represents a product of binomial variable of production unit and the maximum discharge. In this way, it is determined that the variable of discharge is equal to 0 in the hours when the unit is out of operation, as otherwise, its lower and upper limits are determined by the technical minimum and maximum discharge of production unit. The amount of pumped water can be limited through power limits of the pumps (the value of electric power in the hour $t$ corresponds to the value of the electric energy consumed in the same hour at the same constant electric power),

$$
P_{\min , r, p} b p_{r, p, t} \leq P_{r, p, t} \leq P_{\text {maks }, r, p} b p_{r, p, t} .
$$

Similar consideration, as for the expression (21), applies to (27). If the hydropower plant does not have a lower reservoir, values of the minimum and maximum volume of the lower reservoir of the observed hydropower plant are set to a value of 0 , then the values ??of variables that represent volume of the lower reservoir will in all hours equal 0 . If the run-of-the river hydropower plants should be modeled, the minimum and maximum volumes of the upper reservoir are set to the value of 0 . This enables the value of the upper reservoir volume variable to equal 0 at any given time. Therefore, the condition represented by (17) shows that the discharge and spillage of the hydropower plant are equal to the quantity of water that flows through the hydropower plant (there is no possibility of the water accumulation).

The maximum river flow between two hydropower plants is determined by the highest water flow that the riverbed or channel can handle. Also, there is a possibility that for some river systems it is mandatory to ensure a minimum water flow through the riverbed (or channel). Regulating the river flow is possible to achieve under the following condition

$$
Q d_{L, i} \leq Q d_{i, t}+S d_{i, t} \leq Q d_{U, i}
$$

\subsection{The model of the thermal power plant}

The main matter of concern for producers in the short term is whether the income from the production of an additional MWh of electric energy will exceed the additional costs generated by the production of this additional MWh of electric energy. Taking into account the cost of fuel, the heat value of the fuel, and the efficiency of conversion of heat energy into electrical energy, it can be assumed that the production costs of generator $g$ of the thermal power plant $k$ will depend on the level of production $G_{k, g}$, as

$$
C_{k, g}=\alpha_{k, g}+\beta_{k, g} G_{k, g}+\gamma_{k, g} G_{k, g}^{2}
$$

Since for the linear problem, the costs cannot be modeled as a quadratic function of production, the function can be modeled in piecewise linear manner as shown for the discharge curve of the hydropower plant in the previous chapter. Another way is to assume that the value of $\gamma_{k, g}$ is equal to 0 , as it is usually much lower than the coefficient $\beta_{k, g}$. In this case, the coefficient $\beta_{k, g}$ represents the variable cost of production of the generator $g$ in the thermal power plant $k$ [29].

Generators in the thermal power plant with an upper limit of electricity generation, which is determined by the installed capacity, also have a lower limit, which presents the minimum electricity production when the power plant is engaged. The condition can be expressed as

$$
u_{k, g, t} G_{k, g, \min } \leq G_{k, g, t} \leq u_{k, g, t} G_{k, g, \max }
$$

The total energy produced in the thermal power plant $k$ in hour $t$ is

$$
G_{k, t}=\sum_{g=1}^{n g_{k}} G_{k, g, t} \quad(\mathrm{MWh}) .
$$

Starting-up power plant results in costs, because a certain amount of fuel is used for heating the plant to the optimum operating temperature. Start-up costs can be expressed as [29]

$$
C_{\text {start }}(t)=C_{\text {coldstart }}\left(1-e^{-\frac{t}{\tau}}\right)+C_{\text {fixed }}
$$

For start-up costs to be included in the target function, it is necessary to introduce the following start-up binary variables, which equal 1 in an hour when the plant is started, while in other hours, they amount to 0. By simplifying the model, it is assumed that it is necessary to distinguish between cases where the plant is not operating for one hour, two hours, three hours, four hours, and 
Table 1. Characteristics of the wind farms

\begin{tabular}{|c|c|c|c|c|c|c|c|}
\hline \multirow{2}{*}{$\begin{array}{l}\text { Wind } \\
\text { farm }\end{array}$} & \multirow{2}{*}{$\begin{array}{l}\text { Number } \\
\text { of } \\
\text { turbines }\end{array}$} & \multirow{2}{*}{$\begin{array}{c}\text { Turbine } \\
\text { rated power } \\
(\mathrm{MW})\end{array}$} & \multirow{2}{*}{$\begin{array}{l}\text { Type of } \\
\text { wind } \\
\text { turbine }\end{array}$} & \multicolumn{3}{|c|}{ Wind speed $(\mathrm{m} / \mathrm{s})$} & \multirow{2}{*}{$\begin{array}{l}\text { Tower } \\
\text { height } \\
(\mathrm{m})\end{array}$} \\
\hline & & & & $\begin{array}{l}\text { cut } \\
\text { in }\end{array}$ & rated & $\begin{array}{l}\text { cut } \\
\text { out }\end{array}$ & \\
\hline WP1 & 20 & 1.5 & $\begin{array}{c}\text { Ancciona } \\
\text { AW-82/1500 }\end{array}$ & 3 & 10.5 & 20 & 80 \\
\hline \multirow{2}{*}{ WP2 } & 15 & 1 & $\begin{array}{c}\text { Koncar } \\
\text { KO-VA57/1 }\end{array}$ & 2.5 & 12 & 27 & 60 \\
\hline & 1 & 2.5 & Koncar K80 & 2.5 & 12.5 & 25 & 80 \\
\hline WP3 & 14 & 3 & $\begin{array}{c}\text { Siemens } \\
\text { SWT-3.0-101 }\end{array}$ & 3 & 12 & 25 & 80 \\
\hline
\end{tabular}

Table 2. Characteristics of the power plants in the observed hydropower system

\begin{tabular}{lcccc}
\hline $\begin{array}{l}\text { Hydro } \\
\text { power } \\
\text { plants }\end{array}$ & $\begin{array}{c}\text { Installed } \\
\text { capacity } \\
(\mathrm{MW})\end{array}$ & $\begin{array}{c}\text { Technical } \\
\text { minimum } \\
(\mathrm{MW})\end{array}$ & $\begin{array}{c}\text { Design } \\
\text { flow } \\
\mathrm{m}^{3} / \mathrm{s}\end{array}$ & $\begin{array}{c}\text { Useful volume } \\
\text { of upper } \\
\text { reservoir }\left(10^{6} \mathrm{~m}^{3}\right)\end{array}$ \\
\hline HPP1 & $2 \times 47$ & $2 \times 18$ & $2 \times 250$ & 2.8 \\
HPP2 & $2 \times 38$ & $2 \times 15$ & $2 \times 250$ & 10.5 \\
HPP3 & $2 \times 38$ & $2 \times 15$ & $2 \times 250$ & 16.6 \\
PSHPP & $2 \times 210$ & $2 \times 140$ & $\begin{array}{c}2 \times 112.5 \\
(2 \times 85)^{*}\end{array}$ & 6.47 \\
\hline
\end{tabular}

*in pump mode

at least five hours (cold start). For this reason were introduced the binomial variables $p_{k, g}^{1}$ up to $p_{k, g}^{5}$ that signify the launch of the generator depending on how much time elapsed from the moment when the generator is put out of operation.

Because there is a cost if starting variables do not equal zero, a linear optimization of profit maximization will try to adjust that all the starting variables, different than zero, equal zero. Therefore, special restrictions are required to ensure that the correct values are added to the starting variables whenever the plant runs.

$$
\begin{aligned}
p_{k, g, t}^{5} & \geq u_{k, g, t}-u_{k, g, t-1} \\
& -u_{k, g, t-2}-u_{k, g, t-3}-u_{k, g, t-4}-u_{k, g, t-5} \\
p_{k, g, t}^{4} & \geq u_{k, g, t}-u_{k, g, t-1} \\
& -u_{k, g, t-2}-u_{k, g, t-3}-u_{k, g, t-4}-p_{k, g, t}^{5}, \\
p_{k, g, t}^{3} & \geq u_{k, g, t}-u_{k, g, t-1} \\
& -u_{k, g, t-2}-u_{k, g, t-3}-p_{k, g, t}^{4}-p_{k, g, t}^{5} \\
p_{k, g, t}^{2} & \geq u_{k, g, t}-u_{k, g, t-1} \\
& -u_{k, g, t-2}-p_{k, g, t}^{3}-p_{k, g, t}^{4}-p_{k, g, t}^{5} \\
p_{k, g, t}^{1} & \geq u_{k, g, t}-u_{k, g, t-1} \\
& -p_{k, g, t}^{2}-p_{k, g, t}^{3}-p_{k, g, t}^{4}-p_{k, g, t}^{5}
\end{aligned}
$$

\subsection{Objective function}

The objective function of the model is the profit maximization on the day-ahead market for the system in a period of one day. In order to take into account the expected changes in the price of electric energy regarded for a period of several days and the expected rainfall in the following period, it is necessary to take into account the value of the accumulated water in the observed hydropower plants. The simplest method of including the value of water in the model is to determine how much water from each reservoir may that day be harnessed to generate electricity. Another way is to implement in the objective function in the form of maximizing the value of water.

The value of water then depends on how much energy can be produced in hydropower plants with the remaining accumulated water and the expected electricity price at which this energy will be sold. Mathematical notation of the objective function model for the day-ahead market is

$$
\begin{aligned}
\max & \sum_{t=1}^{n_{t}}\left\{\lambda_{t}\left[S_{t}-B_{t}\right]-\sum_{k=1}^{n_{k}} \sum_{g=1}^{n g_{k}}\left[\beta_{k, g} G_{k, t}+C_{k, g}^{5} p_{k, g, t}^{5}\right.\right. \\
+ & \left.\left.C_{k, g}^{4} p_{k, g, t}^{4}+C_{k, g}^{3} p_{k, g, t}^{3}+C_{k, g}^{2} p_{k, g, t}^{2}+C_{k, g}^{1} p_{k, g, t}^{1}\right]\right\} \\
+ & \lambda_{f}\left[\sum_{i=1}^{n_{i}} M u_{i, T} \sum_{k \in \Gamma i} \mu s_{k}+\sum_{i=1}^{n_{i}} M d_{i, T} \sum_{k \in \Gamma j} \mu s_{k}\right]
\end{aligned}
$$

with an additional condition

$\sum_{i=1}^{n_{i}} H_{i, t}+\sum_{k=1}^{n_{k}} G_{k, t}+\sum_{w=1}^{n_{w}} W P s_{w, t}-\sum_{r=1}^{n_{r}} P_{r, t}-S_{t}+B_{t}=L_{t}$.

The first line in (38) represents an income from participating in the market, the second line represents the production costs and the costs of starting-up generators in thermal power plants, and the third line is the value of stored water. The income on the market is represented by the product of the price and difference from sold and purchased electricity on the market. In the hours when it is beneficial, the system can buy electric energy on market. For example, purchased electric energy can be used in the pumped-storage hydropower plant for the operation of pumps in case the expected price of electric energy is relatively small compared to the future price of the water, with little expected production from wind farms, and relatively high production costs of thermal power plants compared to the expected market price. Also, in such conditions the system can use the purchased electricity to 
Table 3. Characteristics of the thermal power plants

\begin{tabular}{lccccc}
\hline $\begin{array}{l}\text { Thermal } \\
\text { power } \\
\text { plants }\end{array}$ & $\begin{array}{c}\text { Installed } \\
\text { capacity } \\
(\mathrm{MW})\end{array}$ & $\begin{array}{c}\text { Fuel } \\
\text { cost } \\
(€ / \mathrm{MWh})\end{array}$ & $\begin{array}{c}\text { Operating and } \\
\text { maintenance } \\
\text { cost }(€ / \mathrm{MWh})\end{array}$ & $\begin{array}{c}\mathrm{CO}_{2} \\
\text { emission } \\
\text { cost }(€ / \mathrm{MWh})\end{array}$ & $\begin{array}{c}\text { Total } \\
\text { marginal } \\
\text { cost }(€ / \mathrm{MWh})\end{array}$ \\
\hline TPP1 & 750 & 12.38 & 4.09 & 16.29 & 32.76 \\
TPP2 & 474 & 8.87 & 9.25 & 2.19 & 20.31 \\
TPP3 & 480 & 41.56 & 3.05 & 7.17 & 51.78 \\
\hline
\end{tabular}

Table 4. Start-up costs

\begin{tabular}{lccccccc}
\hline Thermal & \multirow{2}{*}{$\begin{array}{c}\text { Cold } \\
\text { power }\end{array}$} & Thermal & Thert-up & time & \multicolumn{4}{c}{ Start-up costs $(€)$ after } & an offline period of \\
\cline { 4 - 8 } plants & costs $(€)$ & constants $(\mathrm{h})$ & 1 hour & 2 hours & 3 hours & 4 hours & $\geq 5$ hours \\
\hline TPP1 & 10500 & 2.5 & 3461 & 5782 & 7337 & 8380 & 10500 \\
TPP2 & 7000 & 2.5 & 2307 & 3854 & 4891 & 5586 & 7000 \\
TPP3 & 2000 & 1.2 & 1130 & 1622 & 2000 & 2000 & 2000 \\
\hline
\end{tabular}

Table 5. Local inflow, expected hourly average wind speed and electricity price

\begin{tabular}{|c|c|c|c|c|c|c|c|c|c|}
\hline \multirow{2}{*}{$\begin{array}{c}\text { Hour, } \\
t\end{array}$} & \multicolumn{4}{|c|}{ Local inflow to upper reservoir (HE) } & \multicolumn{4}{|c|}{ Average wind speed $(\mathrm{m} / \mathrm{s})$} & \multirow{2}{*}{$\begin{array}{c}\text { Expected price } \\
(€ / \mathrm{MWh})\end{array}$} \\
\hline & HPP1 & $\mathrm{HPP} 2$ & HPP3 & PSHPP & WP1 & WP2 & WP3 & WP4 & \\
\hline 1 & 475 & 2 & 3 & 14 & 9.02 & 13.95 & 11 & 12.05 & 37 \\
\hline 2 & 475 & 2 & 3 & 14 & 11.26 & 15.21 & 11.26 & 11.98 & 29.7 \\
\hline 3 & 475 & 2 & 3 & 14 & 12.16 & 15.26 & 10.36 & 13.12 & 25.01 \\
\hline 4 & 475 & 2 & 3 & 14 & 14 & 15.1 & 11.9 & 12.16 & 21.9 \\
\hline 5 & 475 & 2 & 3 & 14 & 15.85 & 14.9 & 14.9 & 12.95 & 14.9 \\
\hline 6 & 475 & 2 & 3 & 14 & 15.15 & 15 & 14.1 & 15.15 & 30.75 \\
\hline 7 & 480 & 2 & 3 & 14 & 14.85 & 13.9 & 10.9 & 14.79 & 49.61 \\
\hline 8 & 480 & 2 & 3 & 14 & 13.9 & 13.1 & 11.95 & 15.73 & 57.79 \\
\hline 9 & 480 & 2 & 3 & 14 & 12.85 & 12 & 12 & 15.15 & 62.41 \\
\hline 10 & 480 & 2 & 3 & 14 & 12.7 & 11.8 & 10.8 & 13.75 & 60.5 \\
\hline 11 & 480 & 2 & 3 & 14 & 12 & 11.1 & 10.1 & 14 & 57.22 \\
\hline 12 & 480 & 2 & 3 & 14 & 10.85 & 9.95 & 9.15 & 13.8 & 51.79 \\
\hline 13 & 490 & 2 & 3 & 14 & 8.75 & 8.8 & 9.75 & 13.75 & 47.1 \\
\hline 14 & 490 & 2 & 3 & 14 & 7.75 & 6.7 & 10.74 & 12.65 & 44.94 \\
\hline 15 & 490 & 2 & 3 & 14 & 8 & 9.2 & 11.25 & 11.75 & 46.22 \\
\hline 16 & 490 & 2 & 3 & 14 & 7.6 & 8.75 & 10.8 & 11.65 & 41.87 \\
\hline 17 & 490 & 2 & 3 & 14 & 7.6 & 8.26 & 10.75 & 11.55 & 38.63 \\
\hline 18 & 490 & 3 & 4 & 14 & 8.5 & 8.55 & 10.8 & 10.55 & 37.69 \\
\hline 19 & 490 & 3 & 4 & 14 & 7.25 & 6.45 & 9.8 & 8.26 & 41 \\
\hline 20 & 490 & 3 & 4 & 14 & 6.79 & 4.89 & 9.39 & 7.07 & 49.28 \\
\hline 21 & 490 & 3 & 4 & 14 & 7.04 & 7.06 & 10.46 & 7.87 & 49.54 \\
\hline 22 & 490 & 3 & 4 & 14 & 8.38 & 7.34 & 10.8 & 8.97 & 42.21 \\
\hline 23 & 490 & 3 & 4 & 14 & 8.93 & 8.95 & 10.95 & 10.96 & 48.51 \\
\hline 24 & 490 & 3 & 4 & 14 & 9.73 & 8.7 & 11.8 & 10.95 & 49.72 \\
\hline
\end{tabular}

settle the terms of previously signed bilateral agreement of the production of a certain amount of electricity during certain hours. (39) is a condition of fulfillment of already signed bilateral term contract, whose execution is related to simulation period.

Represented algorithm is used for making offers on the day-ahead market; however, it can also be used for optimal dispatching of the observed system when there is an absence of developed market mechanism, but when the need to satisfy the defined demand is present. In this case, a constant expected price of electric energy is constant, and the needed production is defined by the option of bilateral agreement, limiting the buying and selling bids for day-ahead market to the value of 0 .

\section{CASE STUDY}

\subsection{Model description}

The case study is made on supposed power system based on the real three cascade hydro power plants, one pump storage hydro power plant, three thermal power plants and four wind farms. Characteristics of wind farms are presented in Table 1 [30-33].

The characteristics of the three cascade storage hydro power plants HPP1, HPP2 and HPP3 in the observed hydropower system are shown in Table 2 [34]. Characteristics of pumped-storage hydro power plant (PSHPP) which does not belong to the same basin as mentioned three hydro power plants are also presented in Table 2 [35]. 


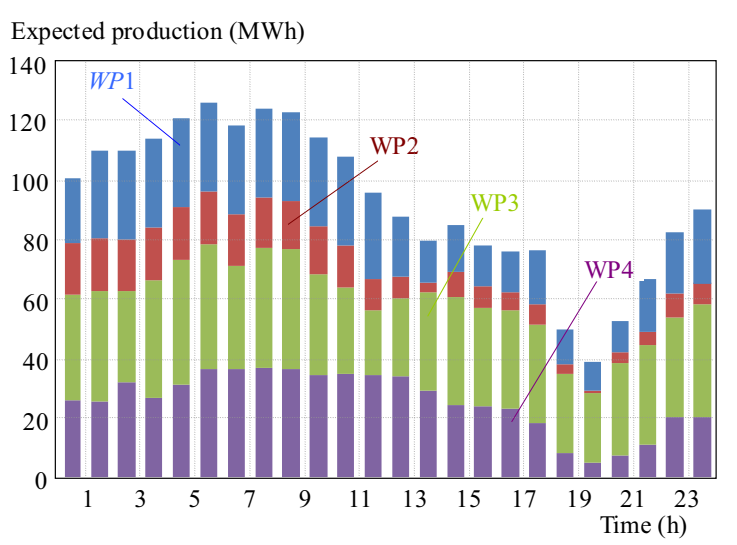

Fig. 4. Expected electricity production in wind farms

Three thermal power plants are considered in observed power system. First one is coal fired thermal power plant with supercritical steam conditions. The second one is coal fired thermal power plant with $90 \%$ of $\mathrm{CO}_{2}$ capture. Third one is Combine Cycle Gas Turbine (CCGT) thermal power plant. Characteristics of the thermal power plants are supposed to average values presented in [36] and shown in Table 3 .

The start-up costs are presented in Table 4 . It is assumed that after offline period of 5 hours, the start-up cost of the coal thermal power plant are equal to cold start-up cost. The start-up cost of the gas thermal power plant are equal to cold start-up cost after offline period of 2 hours.

\subsection{Simulation scenario description}

It is supposed that the observed power system is participating in the day-ahead market as one assembly thus making a joint bid. A deregulated market is supposed in which observed assembly tries to maximize its own profit. Simulation period is 24 hours, from 00:00 till 24:00. It is assumed that in last 5 hours in previous day TPP1 was online and TPP2 and TPP3 was offline. It is assumed that the delay time in which water from HPP1 reaches the upper reservoir of HPP2 is 2 hours. The delay time between HPP2 and upper reservoir of HPP3 is also 2 hours. Due to delay time, it is necessary to know discharges and spillways for HPP1 and HPP2 two hours before simulated period starts. Spillways are assumed to be 0. Start contents of the reservoirs expressed as a percentage of total active storage for HPP1, HPP2, HPP3 and PSHPP are $50 \%, 50 \%, 50 \%$ and $15 \%$, respectively. Discharges of HPP1 and HPP2 in the last two hours of a previous day are $250 \mathrm{HE}$.

The generation of the observed hydro power plants as a function of discharge is divided into 3 segments size of $0.7,0.2$ and 0.1 of the maximal discharge in power plant. Assumed local inflow in upper reservoirs of hydro power plants are presented in Table 5. Expected prices for the simulation scenario shown in Table 5 is the actual electricity prices achieved in EPEX day ahead market in market area France for the 1st of April, 2015. Expected future electricity price is assumed as $40 € / \mathrm{MWh}$. It is assumed that observed assembly is price taker. Furthermore, it is assumed that assembly has signed bilateral agreement for production of $500 \mathrm{MWh}$ in each hour in observed day with price of $50 € / \mathrm{MWh}$.

For each hour of the simulation period, the forecast wind speed in the area of individual wind farm at an altitude of 60 meters above the ground is assumed. Assumed forecast contains 5 possible wind speeds in each hour with the associated probabilities. In Table 5 average hourly values of wind speed in the area of individual wind farm at an altitude of 60 meters above the ground are shown.

According to the tower heights of wind turbines in particular wind farm shown in Table 1, wind speeds in discrete distributions predicted at $60 \mathrm{~m}$ from the ground are calculated to the actual height of the wind turbine tower using the relation (1). The value of the parameter

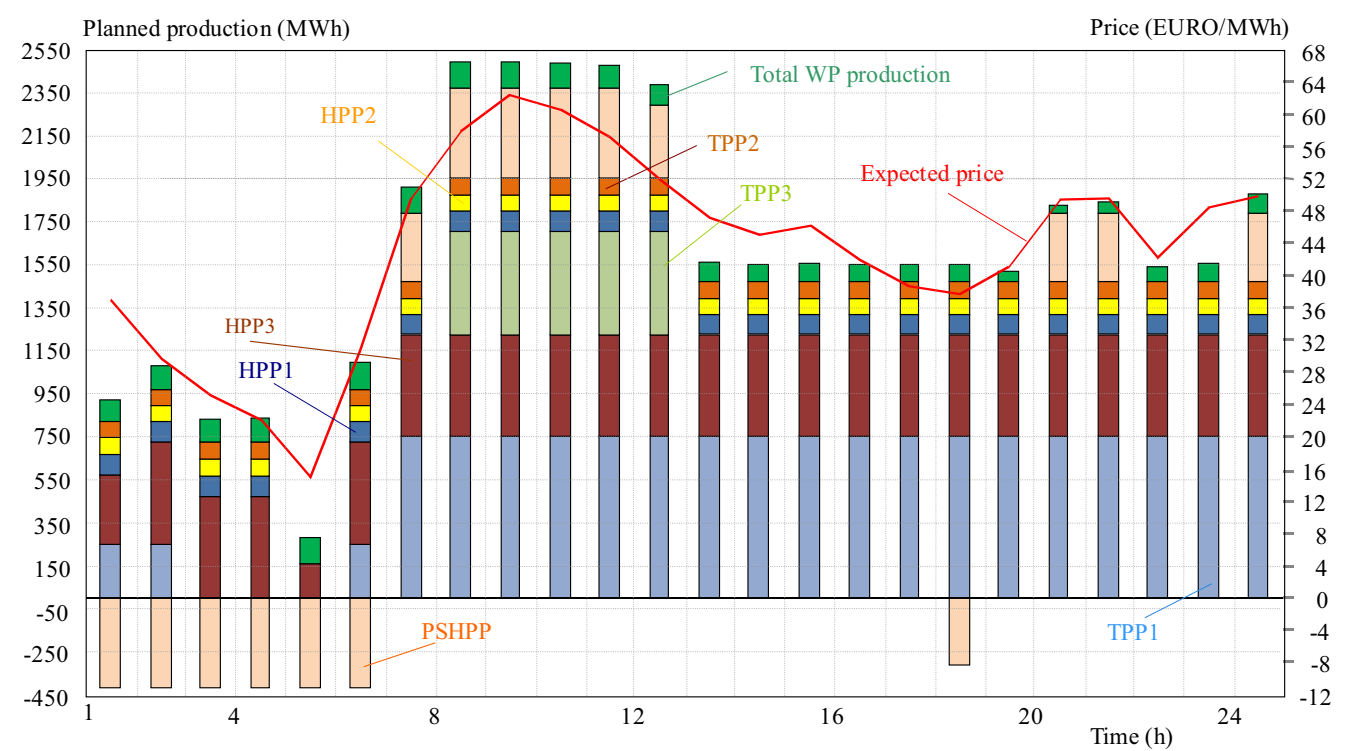

Fig. 5. Electricity production plan 


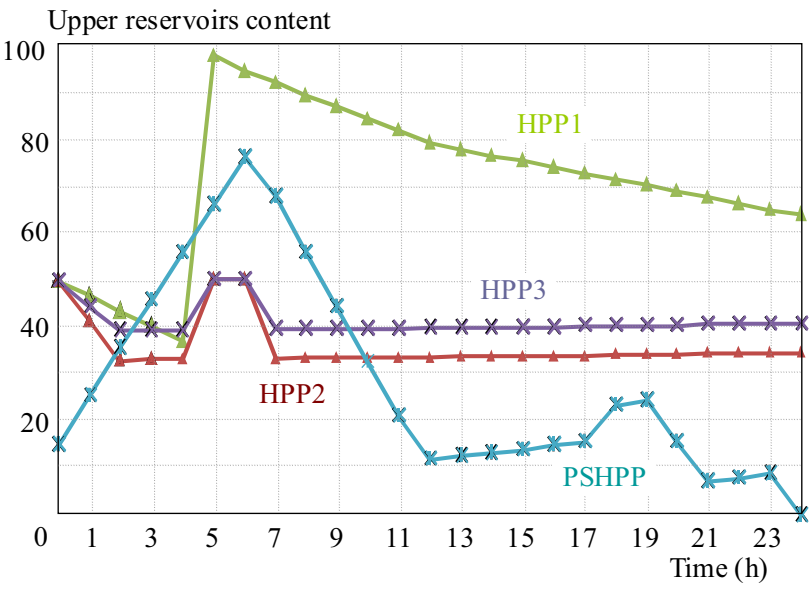

Fig. 6. Volume contents of upper reservoirs

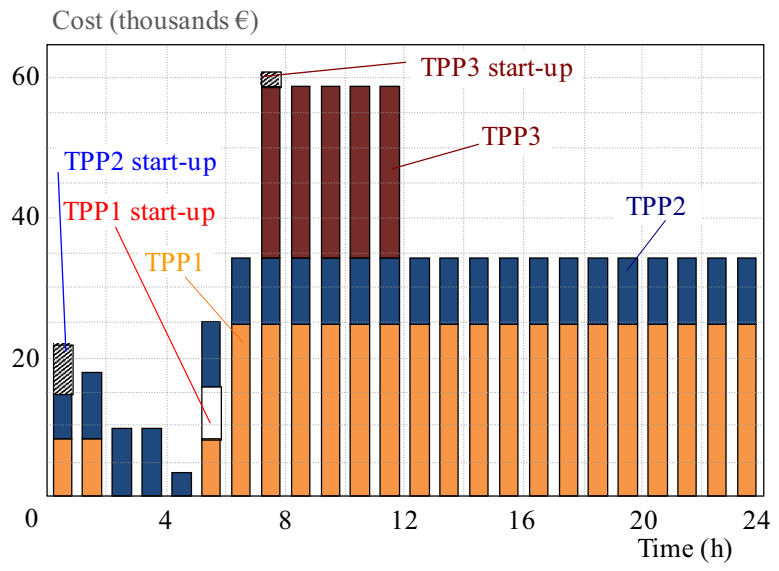

Fig. 7. Production costs of thermal power plants

$z_{0}$ is chosen according to [26], assuming that on the soil surface is low grass $\left(z_{0}=8 \mathrm{~mm}\right)$. Wake factor is supposed to be 0.9 . Using the proposed input-output characteristic shown in Fig. 1, and according to information on wind farms in Table 1, for each wind speed of the discrete distribution, power output is calculated for every hour of each wind farm, thus making the discrete distribution of a wind farm power output for each hour. Using (7), the mean power output of each wind farm during each hour is calculated, representing the expected electricity produced in that hour for each wind farm.

\subsection{Simulation results}

In Fig. 4 expected electricity production in wind farms are presented.

In Fig. 5 generation and consumption of each unit of the assembly are presented.

As can be seen in Fig. 5, PSHPP is in pumping mode during hours with low expected prices. PSHPP is switched to generation mode in hours when expected price is high. As can be seen in Fig. 6, in hours when PSHPP is pumping water, content of its upper reservoir is rising (in hours when PSHPP is offline, the volume is rising slowly due to local inflow). HPP1 and HPP2 are offline in the $5^{\text {th }}$ hour during which water is stored in upper reservoir that will be used in hours when expected price is higher. In the $7^{\text {th }}$ hour, content in upper reservoir of HPP2 is decreasing because inflow is low due to offline period of HPP1 in hour 5 and water flow delay time of 2 hours.

In Fig. 7 TPP production costs are presented.

As can be seen in Fig. 5, TPP3 is generating power only in hour from 8 to 12 due to high marginal costs

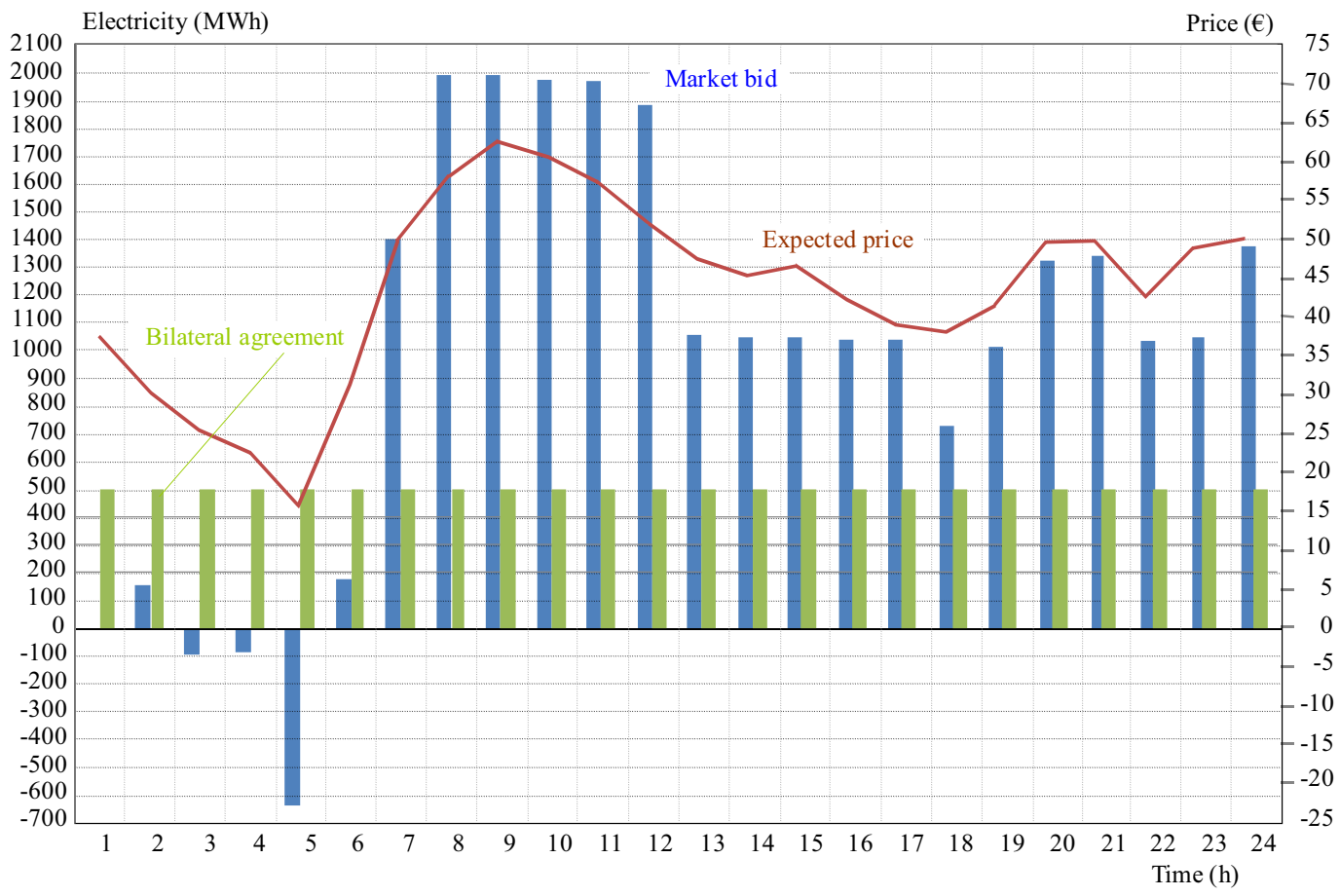

Fig. 8. Market bid plan and bilateral agreement 


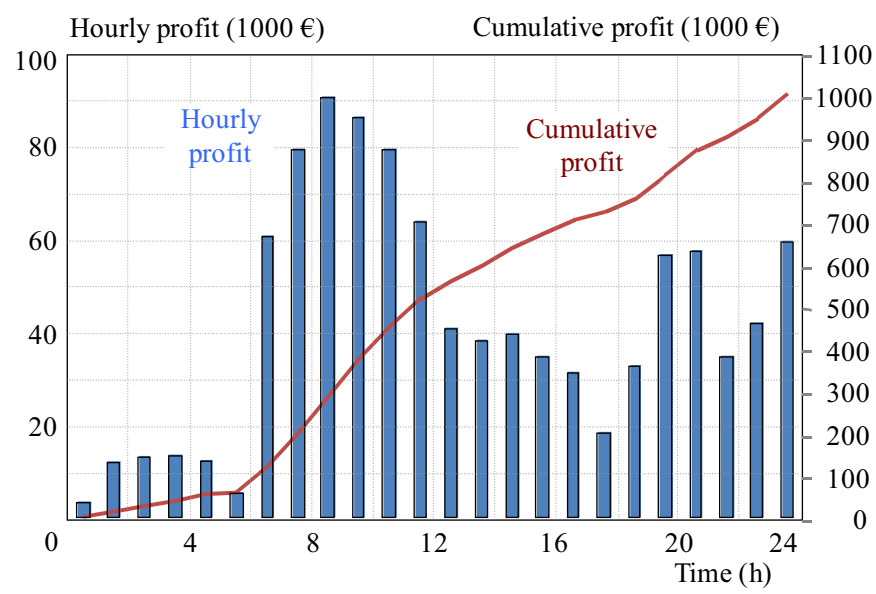

Fig. 9. Expected total hourly profit and cumulative profit

which can only be compensated in these hours. It is economically justified to switch off TPP1 at the beginning of the hour 3 and switch it on at the beginning of the hour 6 , which will generate additional start-up cost.

In Fig. 8 hourly market bids and value of electricity contracted due to bilateral agreement are presented. As can be seen, for the $1^{\text {st }}$ hour market bid is 0 . Total production is used to cover bilateral agreement and consumption of PSHPP in pumping mode.

In hours from 3 to 5 , assembly sets purchasing bid in order to fulfill bilateral agreement and run the pumps in PSHPP. It is economically viable to purchase electricity in these hours because expected prices will compensate only the marginal costs of HPP2 and water will be stored in HPPs for the use in hours with higher expected prices. For example, in the $5^{\text {th }}$ hour WP production is $120 \mathrm{MWh}$, TPP production is $160 \mathrm{MWh}$, which equals total production of $280 \mathrm{MWh}$. On the other hand, consumption of the PSHPP is $420 \mathrm{MWh}$ which together with value of electricity required in bilateral agreement equals $920 \mathrm{MWh}$. Difference of $640 \mathrm{MWh}$ would be purchased on the market.

In Fig. 9 expected assembly total hourly profit and cumulative profit of the observed day are presented.

Total expected profit for the observed day is $1002821 €$. Value of stored water at the end of simulation period is decreased by $46 \%$ compared to the value of stored water at the beginning of the simulation period. Assembly discharges more water than it is stored during observed day because an average expected price in the simulation period is $43.13 €$ which is higher than future expected price of $40 €$.

\section{CONCLUSIONS AND FUTURE WORK}

This paper has presented developed short-term planning algorithm for hybrid power system. Developed mixed integer linear programming model enables coupling hydro cascade system with arbitrary number of different types of hydro power plants (pumped storage, run-of-the river, conventional), different types of thermal power plants and wind farms. Procedure algorithm is applied to the case study in order to show general features of the developed model. The future work can be addressed on stochastic nature of input data such as electricity prices and expected inflow. Further improvement of the procedure algorithm may include more complex market design like intraday markets, regulation markets, etc.

\section{REFERENCES}

[1] ZHANG, L.-LI, Y.: Optimal Energy Management of Hybrid Power System with Two-Scale Dynamic Programming, In Proc. Power Systems Conference and Exposition (PSCE), 2011 IEEE/PES, Phoenix, USA, 20-23 March 2011.

[2] MAtevosyan, J.: On Coordination of Wind and Hydropower, In Proc.7th Int. Workshop on Large-Scale Integration of Wind Power Into Power Systems as well as on Transmission Networks for Offshore Wind Farms, May 2008.

[3] KALDELLIS, J. K.-KAVADIAS, K. A. : Optimal Wind Hydro Solution for Aegean sea islands' Electricity Demand Fulfillment, Applied Energy 70 No. 4 (2001), 333-54.

[4] KALDELLIS, J. K.: Parametrical Investigation of the WindHydro Electricity Production Solution for Aegean Archipelago, Energy Conversion Management 43 (2001), 2097-2113.

[5] KATSAPRAKAKIS, D. A.-CHRISTAKIS, D. G.-PAVLOPOYLOS, K.-PAVLOPOYLOS, S.-PAVLOPOYLOS, I.STEFANAKIS, I.-SPANOS, P. : Introduction of a Wind Powered Pumped Storage System in the Isolated Insular Power System of Karpathos-Kasos, Applied Energy 97 (2012), 38-48.

[6] KALDELlis, J. K.-KAPSALI, M.-KAVADIS, K. A. : Energy Balance Analysis of Wind-Based Pumped Hydro Storage Systems in Remote Island Electrical Networks, Applied Energy 87 No. 8 (2010), 2427-2437.

[7] KAPSAli, M.-KALDELlis, J. K. : Combining Hydro and Variable Wind Power Generation by means of Pumped-Storage under Economically Viable Termsjour Applied Energy.

[8] PAPAEFTHIMIOU, S.-KARAMANOU, E.-PAPATHANASSIOU, S.-PAPADOPOULOS, M.: Operating Policies for Wind-Pumped Storage Hybrid Power Stations in Island Grids, Renewable Power Generation, IET 3 No. 3 (2009), 293-307.

[9] VRettos, E. I.-PAPAThAnASSiOU, S. A. : Operating Policy and Optimal Sizing of a High Penetration RES-BESS System for Small Isolated Grids, IEEE Transactions on Energy Conversion 26 No. 3 (2011), 744-756. 
[10] PAPAEFTHYMiOU, S. V.-KARAMANOU, E. G.-PAPATHANASSIOU, S. A.-PAPADOPOULOS, M. P.: A WindHydro-Pumped Storage Station Leading to High RES Penetration in the Autonomous Island System of Ikaria, IEEE Transactions on Sustainable Energy 1 No. 3 (2010), 163-172.

[11] JARAMILLO, O. A.-BORJA, M. A.-HUACUZ, J. M. : Using Hydropower to Complement Wind Energy: a Hybrid System to Provide Firm Power, Renewable Energy 29 No. 11 (2004), 1887-1909.

[12] BÉLANGER, C.-GAGNON, L. : Adding Wind Energy to Hydro Power, Energy Policy 30 No. 14 (2002), 1279-1284.

[13] BORGHeTti, A.-D'AMBRosio, C.-LODI, A.-MARTELLO, S.: An MILP Approach for Short-Term Hydro Scheduling and Unit Commitment with Head-Dependent Reservoir, IEEE Transactions on Power Systems 23 (2008).

[14] CATALAO, J. P. S.-MARIANO, S. J. P. S.-MENDES, V. M. F.-FERREIRA, L. A. F. M.: Nonlinear Optimization Method for Short-Term Hydro Scheduling Considering Head-Dependency, IEEE Transactions on Electrical Power 20 (2010), 172-183.

[15] GARCA-GONZLEZAND, J.-CASTRO, G.: Short-Term Hydro Scheduling with Cascaded and Head-Dependent Reservoirs based on Mixed-Integer Linear Programming, IEEE Porto Power Tech, Porto, Portugal, 10-13 Sep 2001.

[16] VIERIA, F.-RAMOS, H. M.: Hybrid solution and pumpstorage optimization in water supply system efficiency: A case study, Energy Policy,.

[17] RAHIMIYAN, M.-MORALES, J. M.-CONEJO, A. J. : Evaluating alternative offering strategies for wind producers in a pool, Applied Energy,.

[18] CASTronuOvo, E. D.-PEASLOPES, J. A. : Optimal operation and hydro storage sizing of a wind-hydro power plant, Electrical Power and Energy Systems,.

[19] CAStronuovo, E. D.-PEASlOPES, J. A.: Bounding active power generation of a wind-hydro power plant, In Proc. of the 8th International Conference on Probabilistic Methods Applied to Power Systems.

[20] CASTRonuovo, E. D.-PEAslopes, J. A. : On the optimization of the daily operation of a wind-hydro power plant. IEEE Transaction of Power Systems,

[21] LINDGREN, E.-SÖDER, L.: Minimizing Regulation Cost in Multi-Area Systems with Uncertain Wind Power Forecasts, Wind Energy 11 (2008), 97-108.

[22] ALBADI, M. H.-El-SAADANY, E. F.: Overview of Wind Power Intermittency Impacts on Power Systems, Electric Power Systems Research 80 No. 6 (2010), 627-632.

[23] HOLTTinen, H.-MEiBOM, P.-HUlle, F.-LANGE, B.O'MALLEY, M.-PIERIK, J.-UMMELS, B.-TANDE, J. O.-ESTANQUEIRO, A.-GOMEZ, E.-SDER, L.-STRBAC, G.-SHAKOOR, A.-RICARDO, J.-SMITH, J. C.MILLIGAN,.: Design and Operation of Power Systems with Large Amounts of Wind Power, final report, IEA WIND Task 25, Phase one 2006-2008, VTT Tiedotteita, Espoo, Research Notes 2493, 2009.

[24] TARROJA, B.-MUELLER, F.-EICHMAN, J. D.-SAMUELSEN, S. : Metrics for Evaluating the Impacts of Intermittent Renewable Generation on Utility Load-Balancing, Energy 42 No. 1 (2012), 546-562.

[25] ANGARITA, J. M.-USAOLA, J. G. : Combining Hydro-Generation and Wind Energy: Biddings and Operation on Electricity Spot Markets, Electric Power Systems Researsch 77 (2007), 393-400.

[26] MANWELL, J. F.-McGOWAN, J. G.-ROGERS, A. L. : Wind Energy Explained: Theory, Design and Application, John Wiley \& Sons Ltd, Chichester, 2002.

[27] NIKOLOVSKI, S.-TOPIĆ, D.-FEKETE, K.-SLIPAC, G. : The Influence of Wind Park Krš-Paene on Reliability Indices of $110 \mathrm{kV}$ Transmission Network, In Proc. of 8th International Conference on the European Energy Market (EEM), Zagreb, Croatia, 25-27 May 2011, pp. 870-875.

[28] JOZSA, L.: Energy Processes and Power Plants, Faculty of electrical engineering in Osijek, 2006. (in Croatian)

29] SÖDER, L.-AMELIN, M. : Efficient Operation and Planning of Power System, 8th ed., Royal Institute of Technology, Stockholm, 2007.

[30] ACCIONA Energy Continues its International Expansion by Putting its First Wind Farm in Croatia into Service, http://www.acciona.com/news/acciona-energy-continues-itsinternational-expansion-by-putting-its-first-wind-farm-incroatia-into-service [accessed 18.04.2015].

31] WindPower, Wind Power Plant "Pometeno Brdo", http://www. thewindpower.net/windfarm_en_21010_pometeno-brdo.php [access 18.04.2015].

32] WindPower, Wind Power Plant "Kamensko-Vostane", http:// www.thewindpower.net/windfarm_en_10347_st1-1-st1-2.php [access 18.04.2015].

33] WindPower, Wind Power Plant "Ponikve", http:// www.thewindpower.net/windfarm_en_10347_st1-1-st1-2.php [access 18.04.2015].

[34] Hydro power plants Varazdin, Cakovec, Dubrava, Croatian Electric Utility HEP official web page, http://www.hep.hr/ proizvodnja/en/basicdata/hydro/default.aspx [access 20.04.2015].

35] 30 years of Pumped storage hydro power plant Capljina, http:// www.ephzhb.ba/Publikacije_Vijesnik/Brosura_CHE_web.pdf [access 20.04.2015].

36] Nuclear Energy Agency (NEA), International Energy Agency (IEA). Projected Costs of Generating Electricity 2010 Edition, https://www.oecd-nea.org/?pub/egc/ [access 22.04.2015].

Received 15 June 2015

Goran Knežević, PhD, was born on September 1, 1984. He obtained his diploma degree in 2007 and his $\mathrm{PhD}$ degree in 2013 from the Faculty of Electrical Engineering, J.J. Strossmayer University in Osijek, Croatia. Presently he works as Assistant Professor at the Power System Engineering Department within the Faculty of Electrical Engineering, University in Osijek. His topics of research include electricity markets simulation, energy markets integration, power system economics and cost/benefit assessment, optimization of power system operation, power system analysis.

Zoran Baus, PhD, was born on June 15, 1951. He obtained his BSc degree (1975), MSc degree (1987), in electrical engineering and his PhD degree from the Faculty of Electrical and Computing Engineering, Zagreb, Croatia in 2004. His major fields of interest include Intelligent Control (fuzzy control and optimization) and Power System Analyses. Presently, he is a Full Professor at the Power System Engineering Department at Faculty of Electrical Engineering Osijek, Croatia.

Srete Nikolovski, PhD, was born in Belgrade on October 1, 1954. He obtained his BSc degree (1978) and MSc degree (1989), in electrical engineering at the Faculty of Electrical Engineering, University of Belgrade and his $\mathrm{PhD}$ degree from the Faculty of Electrical and Computing Engineering, University of Zagreb, Croatia in 1993. Currently he is a Full Professor Tenure in the Power System Department within the Faculty of Electrical Engineering, J. J. Strossmayer University in Osijek, Croatia. His main interests are power system modeling, simulation and reliability. 